\title{
Factors associated with waiting times for persons with rheumatic conditions in multidisciplinary pain treatment facilities
}

This article was published in the following Dove Press journal: Journal of Pain Research

\author{
Simon Deslauriers ${ }^{1,2}$ \\ Jean-Sébastien Roy ${ }^{1,2}$ \\ Sasha Bernatsky ${ }^{3-5}$ \\ Debbie E Feldman ${ }^{6-8}$ \\ Anne Marie Pinard ${ }^{1,2,9}$ \\ François Desmeules ${ }^{6,10}$ \\ Mary-Ann Fitzcharles 3,4 \\ Kadija Perreault ${ }^{1,2}$

\begin{abstract}
'Center for Interdisciplinary Research in Rehabilitation and Social Integration (CIRRIS), Québec, QC, Canada; ${ }^{2}$ Faculty of Medicine, Université Laval, Québec, QC, Canada; ${ }^{3}$ McGill University Health Centre (MUHC), Montréal, QC, Canada; ${ }^{4}$ Faculty of Medicine, McGill University, Montréal, QC, Canada; ${ }^{5}$ Research Institute of the McGill University Health Centre (RI-MUHC), Montréal, QC, Canada; ${ }^{6}$ Faculty of Medicine, Université de Montréal, Montréal, QC, Canada;

${ }^{7}$ Centre for Interdisciplinary Research in Rehabilitation of Greater Montreal (CRIR), Montréal, QC, Canada; ${ }^{8}$ Public Health Research Institute of Université de Montréal, Montréal, QC, Canada;

${ }^{9}$ Centre Hospitalier Universitaire (CHU) de Québec, Québec, QC, Canada; ${ }^{10}$ Maisonneuve-Rosemont Hospital (CRHMR) Research Center, Montréal, QC, Canada
\end{abstract}

Correspondence: Kadija Perreault Center for Interdisciplinary Research in Rehabilitation and Social Integration (CIRRIS), 525 Wilfrid-Hamel Boulevard, Quebec, QC GIM 2S8, Canada

Tel +| 418529914 I ext 6853

$\mathrm{Fax}+14185293548$

Email kadija.perreault@fmed.ulaval.ca
Objectives: Access to multidisciplinary pain treatment facilities (MPTF) in Canada is limited by long waiting lists. However, little is known about the factors associated with access to MPTF specifically for persons with rheumatic conditions. This study aimed to 1) determine the waiting time for services in publicly funded MPTF for persons with rheumatic conditions in the province of Quebec, Canada, as well as 2) identify the factors associated with waiting time.

Methods: This study was conducted using the Quebec Pain Registry, a large database of patients who received pain management services in MPTF. Sociodemographic and clinical variables were assessed for potential associations with waiting time. Descriptive, bivariate analyses and multiple linear regression analyses were conducted.

Results: A total of 3,665 patients with rheumatic conditions were identified within the registry. Patients had a mean age of $55 \pm 14$ years and the majority were women $(65.7 \%)$. The average waiting time was $241.2 \pm 308.9$ days (median=126), with $34.2 \%$ of the patients waiting longer than 6 months before having a first appointment. Results indicate that longer pain duration, lower household income, pain onset following a motor vehicle accident, having fibromyalgia, being on permanent disability or unemployed and being referred by a family physician (versus specialist) were significantly associated with longer waiting times. Conclusions: Many patients with rheumatic conditions (especially fibromyalgia) face long delays before receiving services in Quebec's MPTF. This study identified several factors associated with waiting time and emphasizes the need to improve access to pain management services.

Keywords: access, waiting time, rheumatic conditions, chronic pain, multidisciplinary pain treatment facilities

\section{Introduction}

Arthritis and other rheumatic conditions are an increasingly prevalent cause of disability worldwide and result in a substantial individual and societal burden. ${ }^{1,2}$ In North American and European countries, over $20 \%$ of the population has arthritis or another rheumatic condition. ${ }^{2,3}$ These conditions encompass a large variety of diseases and syndromes that are frequently characterized by pain and disability. ${ }^{4}$ Rheumatic conditions may be related to autoimmune disorders (eg, rheumatoid arthritis), be predominantly inflammatory (eg, gout), degenerative (eg, osteoarthritis) or be characterized by widespread body pain (eg, fibromyalgia). ${ }^{4}$

Pain is the main symptom reported by persons with rheumatic conditions, ${ }^{5}$ with a quarter reporting frequent and severe joint pain. ${ }^{6}$ Chronic pain, defined as a pain 
lasting three months or longer, is regarded as a distinct disorder in itself, in part because of the central pain mechanisms often involved in chronic pain. ${ }^{7}$ Multimodal pain management programs that include medical, physical and psychological interventions are often recommended for the treatment of chronic pain. In chronic pain conditions, they have been shown to reduce health care utilization and costs as well as opioid use. ${ }^{8,9}$ These programs have proven effective for patients with fibromyalgia and osteoarthritis by improving pain, fatigue, depressed mood, health-related quality of life, self-efficacy and physical fitness. ${ }^{10,11}$ These programs are often delivered in multidisciplinary pain treatment facilities (MPTF), where various health professionals provide coordinated and patient-centered treatments aimed at reducing pain and disability while empowering patients and improving their quality of life.

Unfortunately, barriers in access to chronic pain treatment in MPTF have been reported in multiple countries around the world. ${ }^{12-14}$ Results from a survey of MPTF conducted in 2006 in Canada, where the majority of MPTF are publicly funded, indicated waiting times for patients with any chronic pain condition extending over 6 months in $50 \%$ of the facilities. ${ }^{12}$ Long waiting times are recognized as the main barrier to MPTF referral by family physicians. ${ }^{15}$ In addition, long delays to access services in MPTF may affect a patient's condition. A systematic review by Lynch et al concluded that a delay of six months or more before receiving chronic pain treatment was associated with a worsening of health-related quality of life and psychological symptoms for patients with various chronic pain conditions. ${ }^{16}$ Another study found a small deterioration in psychological symptoms during a waiting period of three months, ${ }^{17}$ as well as a high financial burden for patients on MPTF waiting lists. ${ }^{18}$ However, these studies on MPTF waiting lists did not focus specifically on patients with rheumatic conditions.

Considering the lack of research investigating access to services in MPTF specifically for patients with rheumatic conditions, along with the high prevalence and substantial burden associated with these conditions, this topic warrants attention. Moreover, identifying the characteristics of patients who wait longer before receiving multidisciplinary pain treatments may inform decisions on resource allocation and prioritization strategies. Accordingly, the objectives of this study were 1) to determine the waiting time to access services in publicly funded MPTF for persons with rheumatic conditions in the province of Quebec, Canada, as well as 2) to identify sociodemographic and clinical factors associated with waiting time.

\section{Methods \\ Data source}

This study was conducted using the data from the Quebec Pain Registry (QPR), a large research database of patients with chronic non-cancer pain who received services within five university-affiliated MPTF in Quebec, Canada's second most populous province. The sociodemographic and clinical data were collected from 2008 to 2014 via a self-administered questionnaire, a structured interview with a research nurse and a physician assessment. Consecutive ambulatory patients aged 18 years and over were enrolled in the QPR database when they were scheduled for a first visit at one of the five participating MPTF. Patients were excluded if they were unable to understand written and spoken French or English or unable to participate due to severe physical or cognitive impairments. A more detailed description of the QPR, including data collection procedures, is available elsewhere. ${ }^{19}$

\section{Study population and selection process}

The National Arthritis Data Workgroup (NADW) case definition of rheumatic conditions was used. ${ }^{20}$ The NADW definition lists a set of arthritis diagnostic codes from the 9th edition of the International Classification of Diseases $(\text { ICD-9-CM })^{20}$ that the Centers for Disease Control and Prevention divided into ten distinct categories: rheumatoid arthritis; fibromyalgia, myalgia and myositis; osteoarthritis and allied disorders; spondylarthropathy; gout and other crystal arthropathies; diffuse connective tissue disease (eg, systemic lupus erythematosus); carpal tunnel syndrome; soft tissue disorders, excluding back; joint pain, effusion and other unspecified joint disorders; other specified rheumatic conditions (see Additional file 1 for the list of NADW ICD9-CM diagnostic codes). ${ }^{21}$ This case definition is recommended for research at the health care system level. ${ }^{22}$

Patients with rheumatic conditions were identified within the QPR as those having either 1) received a diagnosis corresponding to a NADW rheumatic condition by the referring or MPTF's physician, 2) self-reported a comorbidity corresponding to a NADW rheumatic condition or 3) reported a pain onset caused by a NADW rheumatic condition (eg, pain onset due to ankylosing spondylitis). This combination of physician-diagnosed and self-reported rheumatic conditions aimed to include all patients with such conditions.

\section{Variables}

For objectives 1 and 2, waiting time was defined as the number of days between the receipt of the referral at the 
MPTF and the initial visit to the MPTF. To answer objective 2, various sociodemographic and clinical variables available in the QPR were assessed for their association with waiting time, based on the results of previous studies on access to care in different contexts as well as the Andersen's behavioral model of health care utilization (Table 1). ${ }^{23}$ This well-accepted theoretical model conceptualizes individual and contextual determinants of health care utilization that help understand how and why individuals access health services. ${ }^{23}$ Thus, access to and utilization of services are explained by various predisposing characteristics, enabling resources and the need for health services. $^{23}$

\section{Statistical analyses}

Data were checked for deviations from normal distribution, and a log 10 transformation was computed for positively skewed variables to improve skewness and kurtosis. Controlling for the effects of the hospitals or clinics in which data are collected is critical to identify factors associated with waiting time. Thus, in order to control for the variability of waiting time between the five MPTF, the waiting time variable was standardized using z-scores. More specifically, a z-score was calculated for each patient from clinic A using the mean waiting time and standard deviation of clinic $\mathrm{A}$; this procedure was repeated for patients of each clinic.

In order to explore the association between factors and waiting time, bivariate analyses were conducted with the transformed waiting time variable as the dependent variable. Because even negligible differences can reach statistical significance in large datasets, we considered the effect size in addition to the statistical significance as criteria for inclusion in the multiple regression analysis. Thus, variables significantly associated with waiting time $(p<0.05)$ in bivariate analyses and with a minimum effect size of either Hedges' $g>0.2$, eta-squared $\left(\eta^{2}\right)>0.01$ or $R$-squared $>0.02$ (depending on the type of variable) were included in the multiple regression analysis. To account for potential changes in waiting time over the years, the association between waiting time and the date of the first visit to the MPTF was also tested in bivariate analyses. This potential control variable was included in the regression analysis if it met the previously mentioned criteria of statistical significance and effect size. A standard multiple linear regression was computed by entering all independent variables in the regression at once without any backward deletion of variables. ${ }^{24}$ In order to limit the number of dummy variables entered in the regression analysis, categories for certain ordinal variables (eg, household income) were merged based on recursive partitioning analyses that indicated optimal cutoffs. For nominal variables with multiple categories (eg, pain onset, principal source of income, employment status), ANOVA's post-hoc analyses were used to select relevant categories (those with significant differences with other categories) to include as dummy variables in the regression. The pairwise deletion technique was used to handle missing data. Variance inflation factor scores were checked to avoid multicollinearity. Assumptions of normality, linearity and homoscedasticity of residuals were also verified. ${ }^{24}$ The bootstrapping resampling procedure (15,000 samples) was applied to test the regression model stability. ${ }^{24}$ All statistical analyses were computed using SPSS Statistics $^{\mathrm{TM}}$ v25.0 (SPSS Inc., Chicago, IL, USA).

\section{Results}

\section{Study sample}

Among the 8,402 Quebec Pain Registry patients, 3,665 patients $(43.6 \%)$ were identified as having a NADW rheumatic condition (self-reported and/or diagnosed by a physician) and were included in the study; $62.5 \%$ of them were included based on a physician diagnosis and the rest were included based on self-report. The participants' sociodemographic characteristics are summarized in Table 2. Patients had a mean age of $55 \pm 14$ years and the

Table I Potential factors associated with waiting time, based on the Andersen's behavioral model of health care utilization

\begin{tabular}{|l|l|}
\hline Categories & Potential factors \\
\hline Predisposing characteristics & Age, sex, race/ethnicity, education level, civil status, employment status, language, region of residence (urban/rural) \\
\hline Enabling resources & $\begin{array}{l}\text { Household income, income sources, living conditions (eg, alone, with family), disability benefits, litigation related } \\
\text { to disability benefits, type of referring physician }\end{array}$ \\
\hline Need for health services & $\begin{array}{l}\text { Category of rheumatic condition (based on the NADW definition), duration of pain (at the time of referral), pain } \\
\text { onset, number of past or present comorbidities, self-reported diagnoses of anxiety and depression }\end{array}$ \\
\hline
\end{tabular}

Abbreviation: NADW, National Arthritis Data Workgroup. 
Table 2 Sociodemographic characteristics of patients with NADW rheumatic conditions in MPTF $(n=3665)$

\begin{tabular}{|c|c|c|}
\hline Variable & Mean (SD) & Missing n (\%) \\
\hline \multirow[t]{2}{*}{ Age } & $55.3(14.2)$ & $7(0.2)$ \\
\hline & n (\%) & Missing n (\%) \\
\hline Sex & & $2(0.1)$ \\
\hline Female & $2,408(65.7)$ & \\
\hline Male & $\mathrm{I}, 255$ & \\
\hline Race/ethnicity & & $3(0.1)$ \\
\hline Caucasian & $3,396(92.7)$ & \\
\hline Black & $75(2.0)$ & \\
\hline Aboriginal & $48(1.3)$ & \\
\hline Other & 143 (3.9) & \\
\hline First language & & I $(0.03)$ \\
\hline French & $2,715(74.1)$ & \\
\hline English & $621(16.9)$ & \\
\hline Other & $328(8.9)$ & \\
\hline Education (highest completed level) & & $5(0.1)$ \\
\hline None & $16(0.4)$ & \\
\hline Elementary & $337(9.2)$ & \\
\hline High school & $\mathrm{I}, 39 \mathrm{I}(38.0)$ & \\
\hline College & $989(27.0)$ & \\
\hline University & $927(25.3)$ & \\
\hline Civil status & & I (0.03) \\
\hline Single & $818(22.3)$ & \\
\hline Married or common law & $2,04 \mid(55.7)$ & \\
\hline Separated or divorced & $563(15.4)$ & \\
\hline Widowed & $242(6.6)$ & \\
\hline Living conditions & & $37(1.0)$ \\
\hline Alone & $966(26.4)$ & \\
\hline With family & $2,544(69.4)$ & \\
\hline $\begin{array}{l}\text { Other (roommates, no stable liv- } \\
\text { ing conditions or in institutions) }\end{array}$ & $118(3.2)$ & \\
\hline Employment status $^{\mathrm{a}}$ & & I (0.03) \\
\hline Employed (full-time/part-time) & $905(24.7)$ & \\
\hline On permanent disability & $733(20.0)$ & \\
\hline On temporary disability & $576(15.7)$ & \\
\hline Retired & $915(25.0)$ & \\
\hline Unemployed/laid off & $225(6.1)$ & \\
\hline $\begin{array}{l}\text { Other (including student, home- } \\
\text { maker and volunteer) }\end{array}$ & $310(8.5)$ & \\
\hline Household income & & $4(0.1)$ \\
\hline Less than $\$ 20,000$ & 951 (25.9) & \\
\hline$\$ 20,000-34,999$ & $709(19.3)$ & \\
\hline$\$ 35,000-49,999$ & $494(13.5)$ & \\
\hline$\$ 50,000-64,999$ & $350(9.5)$ & \\
\hline$\$ 65,000-79,999$ & $243(6.6)$ & \\
\hline$\$ 80,000$ and more & $481(13.1)$ & \\
\hline Did not wish to answer & $433(11.8)$ & \\
\hline
\end{tabular}

(Continued)
Table 2 (Continued).

\begin{tabular}{|l|l|l|}
\hline Variable & Mean (SD) & Missing n (\%) \\
\hline $\begin{array}{l}\text { Principal source of income } \\
\text { Retirement pension or personal }\end{array}$ & $1,214(33.1)$ & $7(0.2)$ \\
savings & $798(21.8)$ & \\
Employment wages or salary & $48 \mathrm{I}(13.1)$ & \\
Social assistance or employment & & \\
insurance benefits & $454(12.4)$ & \\
Disability benefits from govern- & & \\
ment agency & $382(10.4)$ & \\
Other disability payments & $329(9.0)$ & $7(0.2)$ \\
Other sources of income & & \\
Outstanding litigation related to & & \\
claim & $204(5.6)$ & \\
No & $225(6.1)$ & \\
Yes & $3,229(88.1)$ & \\
Not applicable &
\end{tabular}

Note: ${ }^{a}$ This multiple-choice variable was recoded into a mutually exclusive variable. In cases of multiple answers, priority was given to the "employed" category and then to the "on disability", "retired" and "unemployed" categories.

Abbreviations: NADW, National Arthritis Data Workgroup; MPTF, multidisciplinary pain treatment facilities; SD, standard deviation.

majority were women (65.7\%), Caucasian $(92.7 \%)$ and married or living in common law (55.7\%). Twenty percent were on permanent disability and $45.2 \%$ had an annual household income of less than $\$ 35,000 \mathrm{CDN}$.

The clinical characteristics of patients are presented in Table 3. Patients had a mean pain duration of $7.4 \pm 9.0$ years (mean \pm standard deviation) and a median of 4.0 years (interquartile range $=2-10$ ). A substantial proportion of patients self-reported a diagnosis of depression $(45.4 \%)$ or anxiety (41.1\%). Thirty-four percent of patients waited longer than 6 months before having a first appointment at an MPTF and $62.3 \%$ waited longer than 2 months. There were 435 patients with missing waiting time data; this group did not differ from the rest of the sample in terms of age, sex, diagnosis, pain duration and type of referring physicians $(p>0.05)$.

For the overall sample of patients with NADW rheumatic conditions, the mean waiting time was $241.2 \pm 308.9$ days (median=126; interquartile range $=50-297$ ) (Table 4). Patients with fibromyalgia (with or without other rheumatic conditions) represented $38.1 \%$ of the sample. The proportions of patients with rheumatoid arthritis only or osteoarthritis only were $1.3 \%$ and $21.0 \%$, respectively.

\section{Determinants of waiting time}

For bivariate and regression analyses, two positively skewed variables (waiting time and pain duration) were $\log$ transformed. As previously described, the log- 
Table 3 Clinical characteristics of patients with NADW rheumatic conditions in MPTF $(n=3665)$

\begin{tabular}{|c|c|c|c|}
\hline Variable & n (\%) & $\begin{array}{l}\text { Mean } \\
(\mathrm{SD})\end{array}$ & $\begin{array}{l}\text { Missing } \\
\text { n (\%) }\end{array}$ \\
\hline Pain duration (years) & & $7.4(9.0)$ & $4(0.1)$ \\
\hline $\begin{array}{l}\text { Pain onset circumstance } \\
\text { Following illness } \\
\text { Multiple circumstances } \\
\text { Other circumstances } \\
\text { No precise event } \\
\text { Accident at work } \\
\text { Motor vehicle accident } \\
\text { Following surgery }\end{array}$ & $\begin{array}{l}926(25.3) \\
814(22.2) \\
520(14.2) \\
517(14.1) \\
384(10.5) \\
269(7.3) \\
231(6.3)\end{array}$ & & $4(0.1)$ \\
\hline $\begin{array}{l}\text { Self-reported } \\
\text { comorbidities }^{\text {a }} \\
\text { Depressive disorders } \\
\text { Anxiety disorders } \\
\text { Hypertension } \\
\text { Dyslipidemia } \\
\text { (hypercholesterolemia) } \\
\text { Chronic snoring } \\
\text { Bruxism } \\
\text { Restless leg syndrome } \\
\text { Asthma } \\
\text { Hypothyroidism } \\
\text { Diabetes } \\
\text { Angina/heart attack } \\
\text { Chronic obstructive pul- } \\
\text { monary disease } \\
\text { Stroke (cerebral vascular } \\
\text { accident) } \\
\text { Heart failure }\end{array}$ & $\begin{array}{l}\mathrm{I}, 664(45.4) \\
\mathrm{I}, 505(4 \mathrm{I} . \mathrm{I}) \\
\mathrm{I}, 33 \mathrm{I}(36.3) \\
\mathrm{I}, \mathrm{I} 70(31.9) \\
\mathrm{I}, \mathrm{I} 38(3 \mathrm{I} . \mathrm{I}) \\
905(24.7) \\
740(20.2) \\
719(19.6) \\
575(15.7) \\
487(13.3) \\
376(10.3) \\
17 \mathrm{I}(4.7) \\
145(4.0) \\
109(3.0)\end{array}$ & & $\begin{array}{l}3(0.1) \\
2(0.1) \\
2(0.1) \\
2(0.1) \\
2(0.1) \\
3(0.1) \\
2(0.1) \\
2(0.1) \\
2(0.1) \\
2(0.1) \\
2(0.1) \\
2(0.1) \\
2(0.1) \\
2(0.1)\end{array}$ \\
\hline Number of comorbidities & & $3.0(2.0)$ & $4(0.1)$ \\
\hline $\begin{array}{l}\text { Type of referring physician } \\
\text { Family physician } \\
\text { Medical specialist }\end{array}$ & $\begin{array}{l}1,489(40.6) \\
2,015(55.0)\end{array}$ & & $161(4.4)$ \\
\hline $\begin{array}{l}\text { Waiting time (discrete } \\
\text { categories) } \\
\text { Less than a month } \\
\text { I-2 months } \\
2-6 \text { months } \\
6-12 \text { months } \\
\text { More than } 12 \text { months }\end{array}$ & $\begin{array}{l}514(14.0) \\
433(11.8) \\
1,029(28.1) \\
617(16.8) \\
637(17.4)\end{array}$ & & $\begin{array}{l}435 \\
(11.9)\end{array}$ \\
\hline
\end{tabular}

Note: ${ }^{\text {a }}$ atients could provide more than one answer.

Abbreviations: NADW, National Arthritis Data Workgroup; MPTF, multidisciplinary pain treatment facilities; SD, standard deviation.

transformed waiting time was then standardized based on the mean and standard deviation of each MPTF. Based on bivariate analysis, seven variables were retained for the regression analysis (Table 5). Of these seven variables entered in the standard multiple regression, six remained significantly positively associated with waiting time: longer pain duration, lower household income, pain onset following a motor vehicle accident, having fibromyalgia, being on permanent disability or unemployed and being referred by a family physician. The standard multiple regression resulted in a multiple $R$ of 0.308 (F $(8,2797)$ $=36.569 ; p<0.001)$ and an $R^{2}$ of 0.095 .

\section{Discussion}

This study examined access to services in MPTF for persons with NADW rheumatic conditions and identified several significant sociodemographic and clinical factors associated with waiting time. A considerable proportion (44\%) of patients receiving services in MPTF had a NADW rheumatic condition (self-reported or physiciandiagnosed). Most of these patients had to wait a long period of time to access services in MPTF, with a third of them waiting over 6 months. This is consistent with the findings of another study conducted with patient data from the Quebec Pain Registry, which found a proportion of 35\% of the patients waiting more than 6 months before their initial MPTF visit. ${ }^{19}$ That study included patients with all types of pain conditions, suggesting that the average waiting time for patients with rheumatic conditions may be relatively similar to that of other conditions. As waiting time data for patients with non-rheumatic condition was not available in our study, further comparison between patients with or without rheumatic conditions was not possible.

In our study, the median waiting time was just over 4 months, slightly shorter than the median waiting time of 6 months reported for Canadian MPTF (for any chronic pain condition) in 2006. ${ }^{12}$ However, the differences in populations, settings and methodology (Peng et al used a survey methodology) prevent direct comparison between the two studies.

Nevertheless, these delays considerably exceed the International Association for the Study of Pain's benchmarks for chronic pain treatment, which recommend a 1-month delay for urgent or semi-urgent conditions and 2 months for routine conditions. ${ }^{25}$ Sixty-two percent of our sample did not meet this recommendation. As a result of waiting for chronic pain treatment, patients may experience a deterioration of their health-related quality of life and psychological wellbeing. ${ }^{16,17}$

Other studies from Canada, Europe and Australia report long waiting times for rheumatology care, ${ }^{26}$ for rehabilitation services for persons with rheumatic conditions ${ }^{27}$ and for pain 
Table 4 Waiting time to access services in MPTF based on presentation of rheumatic conditions (NADW diagnostic categories)

\begin{tabular}{|c|c|c|c|c|}
\hline NADW rheumatic conditions & n (\%) & Mean (SD) & Median (interquartile range) & Missing $n$ \\
\hline Any rheumatic condition & $3,665(100)$ & $241.2(308.9)$ & $126(50-297)$ & 435 \\
\hline Joint pain and other unspecified joint disorders & $776(21.2)$ & $198.2(266.3)$ & $98(37-24 I)$ & 83 \\
\hline Fibromyalgia & $774(21.1)$ & $265.1(347.3)$ & $140(66-323)$ & 96 \\
\hline Osteoarthritis & $771(21.0)$ & $222.1(270.2)$ & $132(50-286)$ & 103 \\
\hline Soft tissue disorders & $250(6.8)$ & $169.0(226.5)$ & $90(43-196)$ & 32 \\
\hline Fibromyalgia and osteoarthritis & $192(5.2)$ & $367.5(385.5)$ & $222(72-539)$ & 21 \\
\hline Fibromyalgia and other rheumatic conditions ${ }^{\mathrm{a}}$ & $432($ (II.8) & $316.1(356.1)$ & $161(65-447)$ & 49 \\
\hline Rheumatoid arthritis & $47(1.3)$ & $239.2(295.5)$ & $123(52-244)$ & 6 \\
\hline Other rheumatic conditions $\mathrm{s}^{\mathrm{a}}$ & $423(11.5)$ & $219.7(292.4)$ & $1 / 4(38-272)$ & 45 \\
\hline
\end{tabular}

Note: ${ }^{a}$ Other NADW rheumatic conditions included: spondylosis/spondylitis and allied disorders, carpal tunnel syndrome, diffuse connective tissue disease, gout and other crystal arthropathies, other specified rheumatic conditions.

Abbreviations: MPTF, multidisciplinary pain treatment facilities; NADW, National Arthritis Data Workgroup; SD, standard deviation; Cl, confidence interval.

Table 5 Factors associated with waiting time: results of the standard multiple regression ${ }^{\mathrm{a}}$

\begin{tabular}{|c|c|c|c|c|c|}
\hline \multirow[b]{2}{*}{ Pain duration (log transformed) } & \multirow{2}{*}{$\begin{array}{l}\text { Unstandardized B coefficients } \\
0.299\end{array}$} & \multicolumn{2}{|c|}{$\begin{array}{l}\text { Bootstrap B } \\
95 \% \mathrm{Cl}\end{array}$} & \multirow{2}{*}{$\begin{array}{l}\begin{array}{l}\text { Standardized } \beta \\
\text { coefficients }\end{array} \\
0.197\end{array}$} & \multirow{2}{*}{$\begin{array}{l}P \text { - } \\
\text { value } \\
<0.001\end{array}$} \\
\hline & & 0.252 & 0.361 & & \\
\hline Medical specialist referral ${ }^{b}$ & -0.249 & -0.317 & -0.174 & -0.123 & $<0.001$ \\
\hline Fibromyalgia & 0.127 & 0.026 & 0.171 & 0.062 & 0.001 \\
\hline \multicolumn{6}{|l|}{ Household income ${ }^{c}$} \\
\hline$\$ 35,000-80,000$ & -0.109 & -0.198 & -0.033 & -0.051 & 0.010 \\
\hline$>\$ 80,000$ & -0.214 & -0.338 & -0.125 & -0.076 & $<0.001$ \\
\hline On permanent disability or unemployed & 0.127 & 0.038 & 0.208 & 0.056 & 0.004 \\
\hline Pain onset following motor vehicle accident & 0.198 & 0.034 & 0.307 & 0.052 & 0.004 \\
\hline Receiving social assistance $^{d}$ & 0.063 & -0.117 & 0.135 & 0.020 & 0.323 \\
\hline
\end{tabular}

Notes: ${ }^{a}$ Standard multiple regression with log-transformed standardized waiting time: $R^{2}=0.095$; adjusted $R^{2}=0.092 ; p<0.00 \mathrm{I}$; ${ }^{\mathrm{b}}$ reference category: family physician; ${ }^{c}$ reference category: household income $<\$ 35,000$; ${ }^{d}$ reference category: any other source of income.

Abbreviation: $\mathrm{Cl}$, confidence interval.

management services for persons with chronic pain conditions. $^{13,14}$ Many authors have suggested improving triage processes and increasing supply of services to meet the growing demand for pain services. ${ }^{14}$ Strategies targeting referral prioritization processes and addressing waiting list bottlenecks are warranted. Another potential avenue for improvement is to increase access to multidisciplinary teams able to manage chronic pain conditions within rheumatology departments or at the primary care level, which could be better suited for patients with rheumatic conditions who may not need highly specialized pain interventions. ${ }^{28}$ Supporting primary care physicians and rheumatologists by providing prompt recommendations and advice from chronic pain specialists is another strategy to consider. ${ }^{29}$ The use of technology and social media (eg, online support groups, pain management videos and blogs) ${ }^{30}$ as well as self-management interventions ${ }^{31}$ have also raised interest as innovative ways to reduce patients' burden while waiting for MPTF.

The variables identified in the multiple regression analysis accounted for only $9.5 \%$ of the variance of the waiting time, reflecting the importance of other potential organizational factors that were not available in our study, such as prioritization processes and eligibility criteria. MPTF prioritization processes are reported to vary between facilities and include different prioritization criteria such as pain characteristics and psychological status. ${ }^{32}$ Eligibility criteria may also influence waiting times by limiting the number of referrals. For example, after recent changes in eligibility criteria in one of the included MPTF, patients with fibromyalgia are no longer eligible for treatment and are redirected for management in primary care. This practice, however, may not reflect the current situation in other pain clinics. Other 
organizational factors potentially associated with waiting time include the volume of referrals received and the volume of patients seen at the $\mathrm{MPTF}^{32}$ as well as the type of setting (university-affiliated versus district hospitals) in the case of orthopedic surgery. ${ }^{33}$ Had they been available, such data would likely have accounted for an additional percentage of the variance of the waiting time.

Nevertheless, the multiple regression analysis identified several factors associated with waiting time pertaining to the different categories of determinants described in the Andersen's model. ${ }^{23}$ As opposed to other studies conducted on access and health care utilization with the Andersen's model, ${ }^{34}$ no predisposing characteristic of patients with rheumatic conditions was associated with waiting time. However, several factors related to enabling resources were significantly associated with waiting time. Patients who were on permanent disability or unemployed waited longer than patients with other employment status (ie, employed, retired, temporary disability, other). This is consistent with the results of other studies on waiting time for specialty care or elective surgery $^{33,35}$ and may be explained by an explicit or an implicit prioritization criterion being the potential for return to work. Another factor associated with waiting time was the type of referring physician, with patients referred to MPTF by a family physician waiting longer compared to those referred by medical specialists. This may reflect the need to improve the care pathway from primary care to specialized pain management services. The impact of physicians' characteristics on health services access has also been noted by other researchers. ${ }^{36}$ For example, physicians' gender, age and location have been associated with waiting time for specific medical specialties in Ontario. ${ }^{36}$

Household income was another enabling resource significantly associated with waiting time; lower income patients waited longer before their first visit to the MPTF. This finding is in line with that of other studies reporting barriers in access to various health services for persons of lower socio-economic status, even in publicly funded health systems. ${ }^{37,38}$ Underlying explanations of this finding may involve potential implicit biases in the prioritization of referrals regarding socio-economic status. ${ }^{39}$ This might also be partially explained by the association between lower rate of attendance and lower socio-economic status found in previous studies. ${ }^{40}$ Other studies, however, suggest income is not associated with waiting time. ${ }^{41,42}$ The differences in type of health services (eg, surgery, rehabilitation, medical specialist consultation), settings (eg, outpatient or inpatient hospital departments, primary care setting) and study methodologies make comparisons between studies difficult to interpret. Nonetheless, the possible inequity of access to services in MPTF based on income raises important ethical issues, especially if it has an impact on health outcomes. $^{43}$ In a study by Harrington et al on access to medical specialists, persons with lower income were significantly more likely to report that their life had been affected by the waiting time compared to higher-income individuals. ${ }^{44}$ The World Health Organization advocates that equitable access to services is a key principle of universal health coverage. ${ }^{45}$

The need for health care is also considered to have an influence on access and health care utilization. Need factors associated with longer waiting time included presenting a fibromyalgia condition, having a longer duration of pain and having a pain onset following a motor vehicle accident. Qian et $\mathrm{al}^{46}$ also found a trend towards shorter rheumatology waiting times for patients with inflammatory arthritis such as rheumatoid arthritis compared to conditions such as fibromyalgia. Patients with fibromyalgia represent more than a third of our sample, similar to the proportion found in a previous study, ${ }^{47}$ in which $43 \%$ of the patients with rheumatic conditions referred to an MPTF in Quebec had a diagnosis of fibromyalgia. This large number of patients with fibromyalgia may illustrate the challenges in treating this condition in primary or secondary care, leading to frequent MPTF referrals. Regarding the duration of pain, other studies also reported longer waiting times to access health services for patients with more chronic musculoskeletal conditions. $^{48,49}$ As for the pain onset following a motor vehicle accident, we did not find any literature to support this finding.

\section{Limitations}

This study has some limitations. First, our analyses were limited to the data available. As previously mentioned, it is possible that unavailable variables such as the pain characteristics at the time of referral, the volume of referrals in each MPTF or the prioritization processes could have been associated with waiting time. It would be interesting for future studies to conduct a complete assessment of the patients at the time of referral and also take into account organizational factors (volume of referrals, staff composition, etc.) pertaining to each MPTF. Second, the procedure we used to select patients with rheumatic conditions was not limited to the primary diagnosis and most likely included some patients with rheumatic conditions who were primarily referred for a non-rheumatic condition, which could have affected the waiting times 
for those patients. In the absence of consensus in the literature, we opted for a procedure that would favor a higher sensitivity (likely at the expense of specificity) by selecting patients based on any diagnoses, self-reported comorbidities and pain onsets that matched the NADW case definition. Despite its limitation, self-reported diagnosis is often used in health services research to identify patients from an administrative database. ${ }^{50}$ The NADW case definition was also retained for this study because it had the highest sensitivity compared to two other ICD-9CM-based definitions of rheumatic conditions, ${ }^{50}$ which allowed to maximize case detection. Third, the number of missing data, especially for the waiting time variable, may have altered the analysis. However, no differences were found in the main sociodemographic and clinical variables between the group with missing waiting time data and the rest of the sample. Lastly, our study is subject to limitations inherent to most patient registry studies, including potential inaccuracy of self-reported data, coding errors or inconsistency in the data collection procedures.

\section{Conclusion}

Patients with NADW rheumatic conditions face long delays before accessing services in MPTF, during which their condition may deteriorate. Although a substantial amount of the variance in waiting time remains unexplained, this study identified various factors associated with waiting time. Some of the findings, notably that persons with lower household income waited longer before the initial visit, raise important issues. Longer waiting times for patients referred by a family physician suggest the need to improve the care pathway from primary care to specialized pain management services. In addition, improvement in the provision of services for patients with fibromyalgia seems necessary considering they represent a large proportion of patients referred to MPTF and that they wait a longer period of time before receiving services. Research on service provision and health care trajectory for patients with fibromyalgia from primary to tertiary care is warranted. Finally, the results of this study clearly indicate the magnitude of the challenge for persons with NADW rheumatic conditions to receive services in MPTF and emphasize the need for strategies to improve equitable and timely access to services, including better resource allocation, waiting list management and prioritization of referrals.

\section{Ethics approval}

Ethics approval for this study was obtained from the Institut de réadaptation en déficience physique de Québec
(IRDPQ) Ethics Committee (\#EMP-2015-449). Consent to participate was initially obtained upon enrollment in the Quebec Pain Registry and the current study did not require additional consent.

\section{Acknowledgments}

The research team sincerely thanks Jean Leblond for his guidance in conducting the statistical analyses as well as Éliane Morissette for her contribution to the study. SD received $\mathrm{PhD}$ salary awards from the Arthritis Society, the Ordre professionnel de la physiothérapie du Québec, the Fonds de recherche du Québec Santé (FRQS) and the Canadian MSK Rehab Research Network. This work was supported by the Canadian Initiative for Outcomes in Rheumatology Care (CIORA) grant from the Canadian Rheumatology Association.

\section{Disclosure}

Dr Anne Marie Pinard reports grants from Medisca, personal fees from Allergan and Paladin Labs, speaker fees from Purdue Pharma, Allergan and Paladins Labs outside the submitted work and has served as a member of the external advisory board to Purdue Pharma and Paladin Labs. The authors report no other conflicts of interest in this work.

\section{References}

1. 'Vos T, Allen C, Arora M, Barber RM, Bhutta ZA, Brown A, Carter A, Casey DC, Charlson FJ, Chen AZ, Coggeshall M. Global, regional, and national incidence, prevalence, and years lived with disability for 310 diseases and injuries, 1990-2015. a systematic analysis for the Global Burden of Disease Study 2015. Lancet. 2016;388 (10053): 1545-1602.

2. Barbour KE, Helmick CG, Boring M, Brady TJ. Vital signs: prevalence of doctor-diagnosed arthritis and arthritis-attributable activity limitation - United States, 2013-2015. MMWR Morb Mortal Wkly Rep. 2017;66(9):246-253. doi:10.15585/mmwr.mm6609e1

3. Reis C, Viana Queiroz M. Prevalence of self-reported rheumatic diseases in a Portuguese population. Acta Reumatol Port. 2014;39(1):54-59.

4. van der Heijde D, Daikh DI, Betteridge N, et al. Common language description of the term rheumatic and musculoskeletal diseases (RMDs) for use in communication with the lay public, healthcare providers and other stakeholders endorsed by the European League Against Rheumatism (EULAR) and the American College of Rheumatology (ACR). Ann Rheum Dis. 2018;77(6):829-832. doi:10.1136/annrheumdis-2017-212565

5. Sarzi-Puttini P, Atzeni F, Clauw DJ, Perrot S. The impact of pain on systemic rheumatic diseases. Best Pract Res Clin Rheumatol. 2015;29 (1):1-5. doi:10.1016/j.berh.2015.05.004

6. Barbour KE. Prevalence of severe joint pain among adults with doctordiagnosed arthritis-United States, 2002-2014. MMWR Morb Mortal Wkly Rep. 2016;65(39):1052-1056.

7. Phillips K, Clauw DJ. Central pain mechanisms in the rheumatic diseases: future directions. Arthritis Rheum. 2013;65(2):291-302. doi:10.1002/art.37739 
8. Hooten WM, Townsend CO, Sletten CD, Bruce BK, Rome JD. Treatment outcomes after multidisciplinary pain rehabilitation with analgesic medication withdrawal for patients with fibromyalgia. Pain Med. 2007;8(1):8-16. doi:10.1111/j.1526-4637.2007. 00253. $\mathrm{x}$

9. Sletten CD, Kurklinsky S, Chinburapa V, Ghazi S. Economic analysis of a comprehensive pain rehabilitation program: a collaboration between Florida Blue and Mayo Clinic Florida. Pain Med. 2015;16 (5):898-904. doi:10.1111/pme.12679

10. Hauser W, Bernardy K, Arnold B, Offenbacher M, Schiltenwolf M. Efficacy of multicomponent treatment in fibromyalgia syndrome: a meta-analysis of randomized controlled clinical trials. Arthritis Rheum. 2009;61(2):216-224. doi:10.1002/art.24276

11. Finney A, Healey E, Jordan JL, Ryan S, Dziedzic KS. Multidisciplinary approaches to managing osteoarthritis in multiple joint sites: a systematic review. BMC Musculoskelet Disord. 2016;17:266. doi:10.1186/s12891-016-1134-4

12. Peng P, Choiniere M, Dion D, et al. Challenges in accessing multidisciplinary pain treatment facilities in Canada. Can J Anaesth. 2007;54(12):977-984. doi:10.1007/BF03016631

13. Hogg MN, Gibson S, Helou A, DeGabriele J, Farrell MJ. Waiting in pain: a systematic investigation into the provision of persistent pain services in Australia. Med J Aust. 2012;196(6):386-390.

14. Siddiqui Q, Rangaswamy G. Waiting times for access to a UK multidisciplinary chronic pain service: how do we comply with IASP recommendations? Pain News Br Pain Soc. 2013;11(4):239-241.

15. Lakha SF, Yegneswaran B, Furlan JC, Legnini V, Nicholson K, MailisGagnon A. Referring patients with chronic noncancer pain to pain clinics: survey of Ontario family physicians. Can Fam Physician. 2011;57(3): e106-e112.

16. Lynch ME, Campbell F, Clark AJ, et al. A systematic review of the effect of waiting for treatment for chronic pain. Pain. 2008;136(12):97-116. doi:10.1016/j.pain.2007.06.018

17. Choiniere M, Dion D, Peng P, et al. The Canadian STOP-PAIN project - Part 1: who are the patients on the waitlists of multidisciplinary pain treatment facilities? Can J Anaesth. 2010;57(6):539548. doi:10.1007/s12630-010-9305-5

18. Guerriere DN, Choiniere M, Dion D, et al. The Canadian STOPPAIN project - Part 2: what is the cost of pain for patients on waitlists of multidisciplinary pain treatment facilities? Can J Anaesth. 2010;57 (6):549-558. doi:10.1007/s12630-010-9306-4

19. Choiniere M, Ware MA, Page MG, et al. Development and implementation of a registry of patients attending multidisciplinary pain treatment clinics: the quebec pain registry. Pain Res Manage. 2017;2017:8123812. doi:10.1155/2017/8123812

20. Helmick CG, Lawrence RC, Pollard RA, Lloyd E, Heyse SP. Arthritis and other rheumatic conditions: who is affected now, who will be affected later? National Arthritis Data Workgroup. Arthritis Care Res. 1995;8(4):203-211.

21. Centers for Disease Control and Prevention. National Arthritis Data Workgroup ICD-9-CM diagnostic codes for arthritis and other rheumatic conditions; 2017. Available from: http://www.cdc.gov/arthritis/ data_statistics/pdf/arthritis_codes_2004.pdf. Accessed March 21, $201 \overline{7}$.

22. Helmick CG; United States Bone and Joint Initiative. Arthritis definitions. Available from: http://www.boneandjointburden.org/ 2014-report/iva0/definitions. Accessed March 21, 2017.

23. Andersen RM. Revisiting the behavioral model and access to medical care: does it matter? J Health Soc Behav. 1995;36(1):1-10.

24. Tabachnick BG, Fidell LS. Using Multivariate Statistics. 6th ed. Boston: Pearson Education; 2013.

25. International Association for the Study of Pain. Task force on waittimes. Summary and recommendations; 2017. Available from: http:// www.iasp-pain.org/files/Content/NavigationMenu/ EducationalResources/IASP_Wait_Times.pdf. Accessed May 22017
26. Widdifield J, Bernatsky S, Thorne JC, et al. Wait times to rheumatology care for patients with rheumatic diseases: a data linkage study of primary care electronic medical records and administrative data. CMAJ Open. 2016;4(2):E205-E212. doi:10.9778/ cmajo.20150116

27. Delaurier A, Bernatsky S, Raymond MH, Feldman DE. Wait times for physical and occupational therapy in the public system for people with arthritis in quebec. Physiother Can Physiotherapie Canada. 2013;65(3):238-243. doi:10.3138/ptc.2011-62

28. Peterson K, Anderson J, Bourne D, Mackey K, Helfand M. Effectiveness of models used to deliver multimodal care for chronic musculoskeletal pain: a rapid evidence review. J Gen Intern Med. 2018;33(Suppl 1):71-81. doi:10.1007/s11606-018-4328-7

29. Liddy C, Smyth C, Poulin PA, Joschko J, Sheppard M, Keely E. Supporting better access to chronic pain specialists: the champlain BASE() eConsult service. J Am Board Fam Med. 2017;30(6):766774. doi:10.3122/jabfm.2017.06.170170

30. Merolli M, Gray K, Martin-Sanchez F. Patient participation in chronic pain management through social media: a clinical study. Stud Health Technol Inform. 2016;225:577-581.

31. Lee C, Crawford C, Schoomaker E. Movement therapies for the selfmanagement of chronic pain symptoms. Pain Med. 2014;15(Suppl 1): S40-S53. doi:10.1111/pme.12411

32. Pagé MG, Ziemianski D, Shir Y. Triage processes at multidisciplinary chronic pain clinics: an international review of current procedures. Can J Pain. 2017;1(1):94-105. doi:10.1080/24740527. 2017.1331115

33. Lofvendahl S, Eckerlund I, Hansagi H, Malmqvist B, Resch S, Hanning M. Waiting for orthopaedic surgery: factors associated with waiting times and patients' opinion. Int $J$ Qual Health Care. 2005;17(2):133-140. doi:10.1093/intqhe/mzi012

34. Babitsch B, Gohl D, von Lengerke T. Re-revisiting Andersen's behavioral model of health services use: a systematic review of studies from 1998-2011. Psychosoc Med. 2012;9:Doc11.

35. Clover KA, Dobbins TA, Smyth TJ, Sanson-Fisher RW. Factors associated with waiting time for surgery. Med J Aust. 1998;169 (9):464-468.

36. Jaakkimainen L, Glazier R, Barnsley J, Salkeld E, Lu H, Tu K. Waiting to see the specialist: patient and provider characteristics of wait times from primary to specialty care. BMC Fam Pract. 2014;15:16. doi:10.1186/1471-2296-15-16

37. Laudicella M, Siciliani L, Cookson R. Waiting times and socioeconomic status: evidence from England. Soc Sci Med. 2012;74 (9):1331-1341. doi:10.1016/j.socscimed.2011.12.049

38. Hajizadeh M. Does socioeconomic status affect lengthy wait time in Canada? Evidence from Canadian community health surveys. Eur $J$ Health Econ. 2018;19(3):369-383. doi:10.1007/s10198-017-0889-3

39. Arpey NC, Gaglioti AH, Rosenbaum ME. How socioeconomic status affects patient perceptions of health care: a qualitative study. $J$ Prim Care Community Health. 2017;8(3):169-175. doi:10.1177/ 2150131917697439

40. Ellis DA, McQueenie R, McConnachie A, Wilson P, Williamson AE. Demographic and practice factors predicting repeated non-attendance in primary care: a national retrospective cohort analysis. Lancet Public Health. 2017;2(12):e551-e559. doi:10.1016/S2468-2667(17) 30217-7

41. Thind A, Stewart M, Manuel D, et al. What are wait times to see a specialist? an analysis of 26,942 referrals in southwestern Ontario. Healthc Policy. 2012;8(1):80-91.

42. Sanmartin C, Pierre F, Tremblay S. Waiting for care in Canada: findings from the health services access survey. Healthc Policy. 2006;2(2):43-51.

43. van Doorslaer E, Masseria C, Koolman X, Group OHER. Inequalities in access to medical care by income in developed countries. Cmaj. 2006;174(2):177-183. doi:10.1503/cmaj.050584 
44. Harrington DW, Wilson K, Rosenberg MW. Waiting for a specialist consultation for a new condition in Ontario: impacts on patients' lives. Healthc Policy. 2014;9(4):90-103.

45. World Health Organization. Making Fair Choices on the Path to Universal Health Coverage. Final Report of the WHO Consultative Group on Equity and Universal Health Coverage. Geneva: WHO; 2014.

46. Qian J, Ehrmann Feldman D, Bissonauth A, et al. A retrospective review of rheumatology referral wait times within a health centre in Quebec, Canada. Rheumatol Int. 2010;30(5):705-707. doi:10.1007/ s00296-009-1297-5

47. Fitzcharles MA, Almahrezi A, Ware MA. Clinical profile of rheumatic disease patients referred to a multidisciplinary pain center. $J$ Rheumatol. 2004;31(2):359-363.
48. Passalent LA, Landry MD, Cott CA. Exploring wait list prioritization and management strategies for publicly funded ambulatory rehabilitation services in ontario, canada: further evidence of barriers to access for people with chronic disease. Healthc Policy. 2010;5(4): e139-e156.

49. Quon JA, Levy AR, Sobolev B, et al. The effect of compensation status on waiting time for elective surgical lumbar discectomy. Spine. 2009;34(19):2052-2059. doi:10.1097/BRS.0b013e3181b2f233

50. Murphy LB, Cisternas MG, Greenlund KJ, Giles W, Hannan C, Helmick CG. Defining arthritis for public health surveillance: methods and estimates in four US population health surveys. Arthritis Care Res (Hoboken). 2017;69(3):356-367. doi:10.1002/ acr.22943 


\section{Supplementary material}

Table SI Categories of rheumatic conditions corresponding to the National Arthritis Data Workgroup (NADW) ICD-9-CM diagnostics codes

\begin{tabular}{|c|c|}
\hline Rheumatic conditions categories & NADW ICD-9-CM diagnostics \\
\hline Osteoarthritis and allied disorders & Osteoarthritis and allied disorders (715) \\
\hline Rheumatoid arthritis & RA and other inflammatory polyarthropathies (7I4) \\
\hline Gout and other crystal arthropathies & $\begin{array}{l}\text { Gout }(274) \\
\text { Crystal arthropathies }(7 \mid 2)\end{array}$ \\
\hline Spondylosis/spondylitis and allied disorders & $\begin{array}{l}\text { AS/inflammatory spondylopathies }(720) \\
\text { Spondylosis and allied disorders }(721) \\
\text { Reiter's Disease }(99.3) \\
\text { Psoriatic arthopathy }(696.0)\end{array}$ \\
\hline Diffuse connective tissue disease & Diffuse connective tissue disease $(710)$ \\
\hline Fibromyalgia, myalgia and myositis & Myalgia and myositis unspecified (729.1) \\
\hline Carpal tunnel syndrome & Carpal tunnel syndrome $(354.0)$ \\
\hline Soft tissue disorders & $\begin{array}{l}\text { Peripheral enthesopathies and allied disorders }(726) \\
\text { Other disorders of synovium/tendon/bursa }(727) \\
\text { Disorders of muscle/ligament/fascia }(728.0-728.3,728.6-728.9) \\
\text { Rheumatism, unspecified and fibrositis }(729.0) \\
\text { Fascitis, unspecified }(729.4)\end{array}$ \\
\hline Joint pain, effusion and other unspecified joint disorders & $\begin{array}{l}\text { Other unspecified arthropathies }(7|6.1,716.3-7| 6.6,716.9) \\
\text { Other and unspecified joint disorders }(7 \mid 9.0,719.4-719.9)\end{array}$ \\
\hline Other specified rheumatic conditions & $\begin{array}{l}\text { Arthritis associated with infections }(7 \mid I) \\
\text { Arthropathy associated with disorders classified elsewhere }(7 \mid 3) \\
\text { Specified arthropathies }(7|6.0,7| 6.2,7 \mid 6.8) \\
\text { Specified joint disorders }(7|9.2,7| 9.3) \\
\text { Polymyalgia rheumatica }(725) \\
\text { Syphilis of muscle }(95.6) \\
\text { Syphilis of synovium/tendon/bursa }(95.7) \\
\text { Gonococcal infection of joint (98.5) } \\
\text { Behcet's syndrome (I36.I) } \\
\text { Other disorders purine/pyrimidine metabolism (277.2) } \\
\text { Allergic purpura (287.0) } \\
\text { Cauda equina syndrome (344.6) } \\
\text { Brachial plexus/thoracic outlet lesions (353.0) } \\
\text { Tarsal tunnel syndrome (355.5) } \\
\text { Polyneuropathy in collagen vascular disease (357.I) } \\
\text { Rheumatic fever w/o heart disease (390) } \\
\text { Rheumatic fever w/heart disease (39I) } \\
\text { Cerebral arteritis (437.4) } \\
\text { Raynaud's syndrome (443.0) } \\
\text { Polyarteritis nodosa and allied conditions (446) } \\
\text { Arteritis, unspecified (447.6) }\end{array}$ \\
\hline
\end{tabular}

Note: Centers for Disease Control and Prevention. National Arthritis Data Workgroup ICD-9-CM diagnostic codes for arthritis and other rheumatic conditions. Atlanta, GA: CDC; 2004. Available from: http://www.cdc.gov/arthritis/data_statistics/pdf/arthritis_codes_2004.pdf.' 


\section{Reference}

1. Centers for Disease Control and Prevention. National Arthritis Data Workgroup ICD-9-CM diagnostic codes for arthritis and other rheumatic conditions. Atlanta, GA: CDC; 2004. Available from: http:// www.cdc.gov/arthritis/data_statistics/pdf/arthritis_codes_2004.pdf. Accessed March 21, 2017.

\section{Publish your work in this journal}

The Journal of Pain Research is an international, peer reviewed, open access, online journal that welcomes laboratory and clinical findings in the fields of pain research and the prevention and management of pain. Original research, reviews, symposium reports, hypothesis formation and commentaries are all considered for publication. The manuscript management system is completely online and includes a very quick and fair peer-review system, which is all easy to use. Visit http:// www.dovepress.com/testimonials.php to read real quotes from published authors. 